\title{
Follow-up of internal mammary artery stent with 64-slice CT
}

\author{
Filippo Cademartiri · Alessandro Palumbo · \\ Erica Maffei - Giancarlo Casolo • \\ Nico R. A. Mollet · Bob W. Meijboom • \\ Jurgen M. Ligthart
}

Received: 27 August 2006/ Accepted: 21 September 2006/ Published online: 9 February 2007

(C) Springer Science+Business Media B.V. 2007

\begin{abstract}
We present a case of 81-year-old woman complaining chest pain after minimal efforts who underwent multiple coronary artery bypass grafts (CABGs) during the last 15 years. A significant in-stent re-stenosis was found at ostium of left internal mammary artery (LIMA). A non-invasive CT coronary angiography (CT-CA) was performed after 6-month follow-up. CT-CA is a reliable non-invasive technique for the follow-up of stents in coronary artery bypass grafts.
\end{abstract}

Keywords 64-slice CT $\cdot$ CT angiography $\cdot$ Left internal mammary artery · Diagnosis · Follow-up · Stent $\cdot$ Coronary artery bypass graft

Electronic supplementary material The online version of this article (doi: 10.1007/s10554-006-9172-x) contains supplementary material, which is available to authorized users

F. Cademartiri - A. Palumbo - N. R. A. Mollet .

B. W. Meijboom · J. M. Ligthart

Department of Radiology and Cardiology, Erasmus

Medical Center, Rotterdam, Netherlands

F. Cademartiri $(\varangle) \cdot$ A. Palumbo · E. Maffei

Non-invasive cardiovascular Imaging Unit,

Department of Radiology and Cardiology, Azienda

Ospedaliero-Universitaria di Parma, Via Gramsci,

14, Parma 43100, Italy

e-mail: filippocademartiri@hotmail.com

G. Casolo

Department of Cardiology, Ospedale "Versilia",

Viareggio, Italy

\section{Introduction}

Stenoses of the Left Internal Mammary Artery (LIMA) coronary bypass are rarely described in the Literature [1]. Stenoses of the left subclavian artery (LSA) are more frequently reported [2]. Due to the infrequent occurrence of stenoses, LIMA's stenting is not commonly performed with the exception of the distal anastomosis [3, 4].

Stent follow-up can be performed with non-invasive techniques. Computed Tomography (CT) coronary angiography is becoming a reliable alternative to conventional catheter coronary angiography for the assessment of coronary artery stenosis. For the stent follow-up CT is becoming increasingly reliable. In particular the latest introduction of 64-slice CT technology has increased the performance in terms of spatial and temporal resolution.

We present a case of PCI of ostial LIMA stenosis with non-invasive 6-month follow-up using Computed Tomography Angiography (CTA).

\section{Case description}

A 81-year-old woman underwent coronary artery bypass grafts (CABG) in december 1992 underwent CABG surgery with LIMA to LAD, diagonal branch and marginal branch.

In september 2001, after 9 years, a bare metal stent $(3.5 \times 13 \mathrm{~mm})$ was placed at the ostium of the LIMA. 


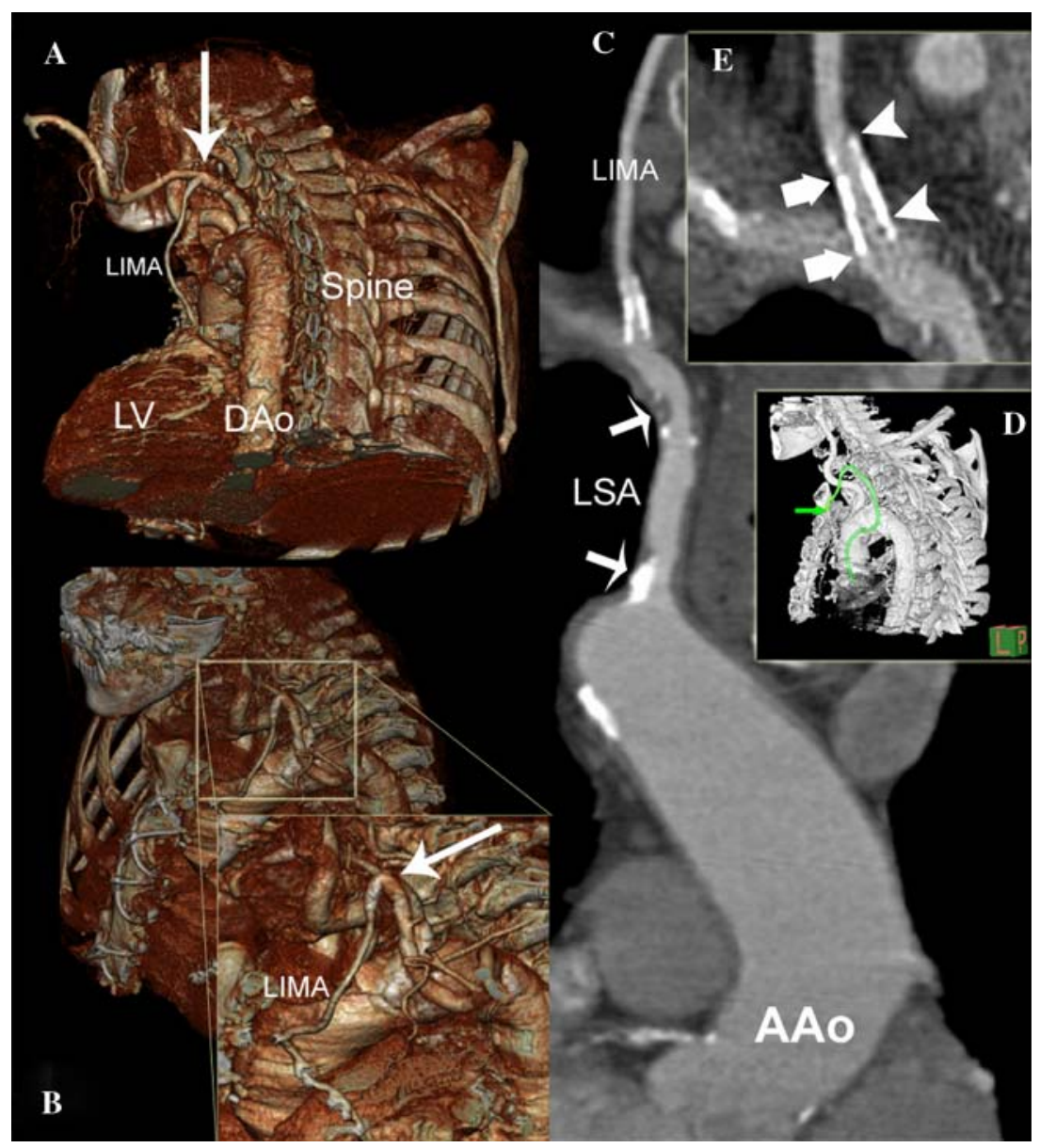

Fig. 1 (A-B) Volume Rendering of the upper thorax: vascular anatomy is clearly depicted. The arrow in the magnified box indicates the proximal part of the LIMA. (C) Curved thin-MIP along the center-line of ascending aorta, left subclavian artery (LSA) and LIMA. (D) Reference image for the path of central linear line: a mixed plaque at the LSA ostium and a soft plaque in the distal third of the same vessel are displayed. The LIMA

In march 2005 the patient underwent PCI for in-stent re-stenosis in the same location with a drug-eluting stent [5].

The patient underwent 6-month follow-up with 64-slice coronary CTA (Sensation 64 Cardiac $^{\circledR}$, Siemens, Germany) with the following parameters: individual detector width $0.6 \mathrm{~mm}$, gantry rotation time $330 \mathrm{~ms}$, effective temporal resolution $165 \mathrm{~ms}$ (with single segment reconstruction algorithm), kV 120, eff. mAs 850, scan time $15 \mathrm{~s}$. A bolus of $80 \mathrm{ml}$ contrast material with high iodine concentration (iomeprol, $400 \mathrm{mg}$ of Iodine shows adequate intra-luminal enhancement. (E) Magnified view of the ostium of the LIMA covered by the stent: arrows indicate the drug-eluting stent protruding into the subclavian lumen. Arrowheads outline the Penta stent previously placed. Stent is patent and no signs of restenosis are present. Aao, ascending aorta; Dao, descending aorta; LIMA, left internal mammary artery; LSA, left subclavia artery; LV, left ventricle

per $\mathrm{ml}$; Iomeron $^{\circledR}$, Bracco, Milan, Italy) was injected through the brachial vein with a flow rate of $4 \mathrm{ml} / \mathrm{s}$.

The reconstructed images showed the patency of the LIMA stent and no signs of in-stent restenosis (Fig. 1).

\section{Discussion}

We report the capabilities of coronary CTA for the non-invasive assessment of stent patency at 
follow-up. Stents are characterized (similarly to calcifications) by high density. At CT, the high attenuation determines an enlargement of the apparent size of the metal struts. This artifacts is defined as "blooming" and is due to several factors, such as interpolation and partial volume. The artifact is more evident with higher stent density and low stent diameter size [6]. Coronary stent evaluation is hampered by the fact that vessels are small (the artifact effect is in the same range of the diameter of the vessels) and they move according to heart-beat [7].

Patient's LIMA was a small vessel and degree of balloon dilatation was minimal. Nevertheless, LIMA is not affected by cardiac motion and therefore image quality was satisfactory, allowing a in-stent visualization (see Electronic supplementary material (Movie 1 and 2)).

The case report shows follow-up of an asymptomatic patient with previous stent implantation: it can be performed safely and reliably with 64slice CT-CA, and have no particular contraindication [8-10].

\section{References}

1. Tengiz I, Alyev E, Ercan E 2005 An alternative percutaneous interventional approach for postanastomatic left anterior descending artery stenosis in patients with markedly tortuous LIMA graft. Int J Cardiovasc Imaging 21:491-494

2. Patel S, Coltart J, Sabharwal T 2006 Left subclavian artery and left anterior descending coronary artery stenoses: obstacles to the left internal mammary artery. Heart 92:320

3. Spencer CG, Lip GY 2001 Left internal mammary graft stenosis and restenosis following angioplasty and stenting. Heart. 86:E9

4. Kockeritz U, Reynen K, Knaut M et al 2004 Results of angioplasty (with or without stent) at the site of a narrowed coronary anastomosis of the left internal mammary artery graft or via the internal mammary artery. Am J Cardiol 93:1531-1533

5. Morice MC, Serruys PW, Sousa JE et al 2002 A randomized comparison of a sirolimus-eluting stent with a standard stent for coronary revascularization. $\mathrm{N}$ Engl J Med 346:1773-1780

6. Mahnken AH, Muhlenbruch G, Seyfarth T et al 2006 64-slice computed tomography assessment of coronary artery stents: a phantom study. Acta Radiol 47:36-42

7. Pugliese F, Cademartiri F, van Mieghem C et al 2006 Multidetector CT for visualization of coronary stents. Radiographics 26:887-904

8. Cademartiri F, Mollet NR, Lemos PA et al 2005 Usefulness of multislice computed tomographic coronary angiography to assess in-stent restenosis. Am J Cardiol 96:799-802

9. Seifarth H, Hozgun M, Raupach M et al 2006 64Versus 16-slice CT angiography for coronary artery stent assessment: in vitro experience. Invest Radiol. 41:22-27

10. Jones CM, Athnasiou T, Dunne N et al 2006 Multislice computed tomography in coronary artery disease. Eur J Cardiothorac Surg. 30:443-450 